\title{
Renal involvement in diffuse large B-cell lymphoma: A case report
}

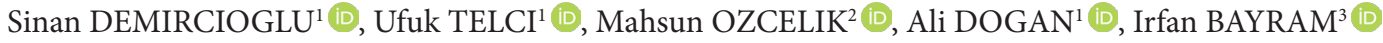 \\ Department of Hematology, School of Medicine, Van Yuzuncu Yil University, Van, Turkey \\ Department of Nuclear Medicine, School of Medicine, Van Yuzuncu Yil University, Van, Turkey \\ Department of Pathology, School of Medicine, Van Yuzuncu Yil University, Van, Turkey \\ Corresponding Author: Sinan DEMIRCIOGLU \\ E-mail: sinandemircioglumd@gmail.com
}

Submitted: $08.07 .2019 \quad$ Accepted: 28.08.2019

\section{ABSTRACT}

Diffuse large B-cell lymphoma is the most common subtype of non-Hodgkin lymphoma. Approximately $40 \%$ of cases have extranodal involvement. Renal involvement is rare, however, it is associated with poor prognosis. Furthermore, renal involvement increases the risk of central nervous system (CNS) recurrence. Therefore, it is recommended that CNS prophylaxis should be included in lymphoma treatment in cases of renal involvement.

Keywords: Diffuse large B-cell lymphoma, Extranodal, Kidney, Involvement

\section{INTRODUCTION}

Lymphomas are malignant neoplasms originating from lymphoid cells. They are classified under two categories as Hodgkin lymphoma and non-Hodgkin lymphoma (NHL). Diffuse large B-cell lymphoma (DLBCL) constitutes $30 \%-58 \%$ of all NHLs. There are 3-4/100,000 new cases per year in the European Union, and its incidence increases with age [1]. Extranodal involvement occurs in approximately $40 \%$ of DLBCL cases (with $36 \%$ in the gastrointestinal tract, 20\% in the head and neck region and $14 \%$ in the bone marrow) [2]. Renal involvement, which is rare, occurs in $1 \%-2 \%$ of DLBCL patients [3-5].

\section{CASE REPORT}

A 74-year-old female with a history of hypertension, diabetes mellitus and coronary artery disease presented at our hospital with complaints of weight loss and abdominal pain that had been persisting for a month. Physical examination revealed tenderness in the abdomen. An abdominal ultrasound scan showed a vascularised heterogeneous hypoechoic lesion of approximately $7.5 \times 5.5 \mathrm{~cm}$ in the left kidney and two hypoechoic lesions with a diameter of $8.5 \mathrm{~cm}$ that surrounded the vascular structures in the pancreatic duct and adjacent to the left iliac artery. Positron emission tomography/computed tomography (PET/CT) scan showed a pathological increase in 18-fluoro-2-deoxyglucose (18F-FDG) uptake, lymphadenopathies in the right mediastinal region $\left(\mathrm{SUV}_{\max }: 8.9\right)$, a mass with a diameter of approximately $9 \times 6.5 \times 10.5 \mathrm{~cm}$ in the pancreatic duct $\left(\mathrm{SUV}_{\max }: 27.9\right)$ and $\mathrm{a}$ mass with a diameter of $9 \times 6 \mathrm{~cm}$ in the left kidney $\left(\mathrm{SUV}_{\max }\right.$ : 26.5). Conglomerate lymph nodes, the largest one being $5 \times$ $3.5 \mathrm{~cm}$, were observed on the mesenteric, para-aortic, left main iliac and right iliac chain $\left(\mathrm{SUV}_{\max }: 26.0\right)$ (Figure 1). The tru-cut biopsy results performed at the pancreatic duct and left kidney indicated non-germinal centre diffuse large B-cell lymphoma [vimentin (+), LCA (+), CD20 (+), CD10 (-), BCL-6 (+), BCL-2 (-), MUM-1 (+), p53 (+) and KI67 index of 98\%] (Figure 2). Laboratory test results showed that hemoglobin level was 13.48 $\mathrm{g} / \mathrm{dl}$, leukocyte count was $7.95 \mathrm{~mm}^{3}$, platelet count was 377,000 , creatinine level was $0.79 \mathrm{mg} / \mathrm{dl}$, LDH level was $510 \mathrm{U} / \mathrm{L}$, Eastern Cooperative Oncology Group (ECOG) performance score was 3, Ann Arbour stage was 4 and international prognostic index (IPI) score was 5 (high). Owing to old age and poor performance, the patient was initiated on R-mini-CHOP (rituximab plus cyclophosphamide, doxorubicin, vincristine, prednisone) treatment. Cerebrospinal fluid test results did not reveal any involvement. Intrathecal methotrexate was administered for CNS prophylaxis.

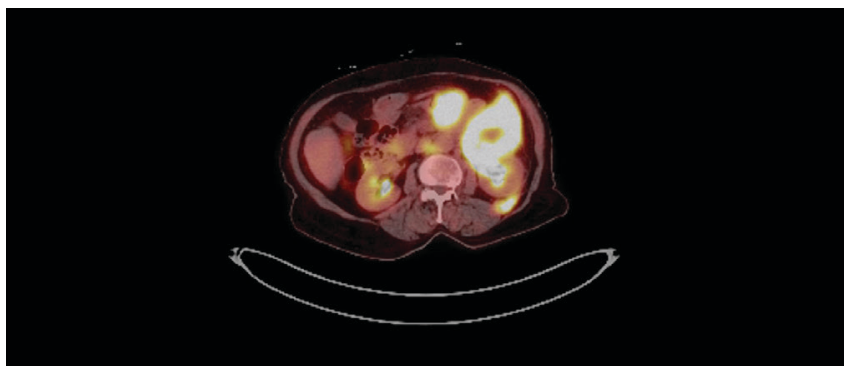

Figure 1. In the left kidney, peripheral and pathological increase in $18 \mathrm{~F}-\mathrm{FDG}$ uptake is observed in a soft tissue mass that has a hypodense hypometabolic area (necrosis) at its center.

How to cite this article: Demircioglu S, Telci U, Ozcelik M, Dogan A, Bayram I. Renal involvement in diffuse large B-cell lymphoma: A case report. Marmara Med J 2019; 32: 144-146. doi: 10.5472/marumj.638192 


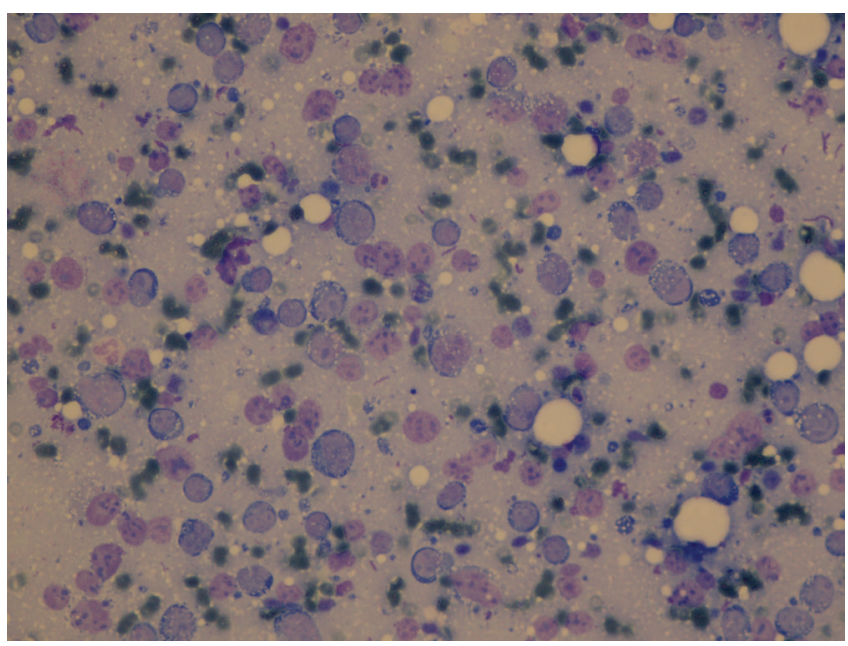

Figure 2. Renal biopsy findings were compatible with DLBCL: Atypical lymphocytes singly scattered on a base consisting of erythrocytes and lymphoglandular bodies, having a cytoplasm with vacuoles, nuclear pleomorphism and irregular nuclear contours and prominent nuclei, are observed in the smear (MGG staining, original magnification $40 \times$ with objective lens).

\section{DISCUSSION}

In a study with 821 patients diagnosed with DLBCL, renal involvement was noted in $22(3 \%)$ of them at the time of diagnosis. Among the patients with renal involvement, $86 \%$ had advanced stage DLBCL with high IPI scores and 32\% had renal insufficiency. It was demonstrated that renal involvement leads to a 3-year progression-free survival (PFS) rate of $44 \%$ and a 3 -year overall survival (OS) rate of $52 \%$, indicating that the survival rates are worse with renal involvement than without renal involvement. In addition, it was observed that the rate of CNS recurrence was high (36\%) [6]. In other studies, renal involvement was found to be an independent risk factor for CNS recurrence [7-9]. Intrathecal methotrexate administration is the most widely used prophylaxis method for the risk of CNS in high-risk patients. However, recent studies have demonstrated this method to be insufficient in reducing the risk of CNS recurrence $[10,11]$. Conclusions concerning the insufficiency of intrathecal treatment for the prevention of parenchymal CNS recurrence have led to the administration of intravenous highdose methotrexate as CNS prophylaxis. The positive effect of intravenous high-dose methotrexate administration in patients with a high risk for CNS recurrence has been demonstrated in many studies $[12,13]$. Our patient had no CNS involvement at the time of diagnosis. Owing to old age and a low-performance score, intrathecal methotrexate was included in our patient's treatment regimen instead of high-dose methotrexate for CNS prophylaxis.

Several published studies on DLBCL patients treated with $\mathrm{R}$-CHOP-like regimens have reported the 3 -year PFS rate to be $62 \%-79 \%$ and the 3 -year OS rate to be $72 \%-93 \%$ [14-17].
Extranodal involvement at multiple sites has been identified as an independent risk factor for NHL [18]. Additionally, renal involvement has been demonstrated to be associated with poorer survival [6]. It is known that acute kidney damage adversely affects survival in patients with hematological malignancy [19]. In one study, one-third of patients with DLBCL with renal involvement had renal failure. The presence of renal failure was associated with poor outcome [6]. In our patient, renal failure was not identified at the time of diagnosis.

Following the discovery of rituximab, the R-CHOP chemotherapy regimen (rituximab plus cyclophosphamide, doxorubicin, vincristine, prednisone) has been accepted as the standard treatment approach in DLBCL [15, 20-23]. However, it is recommended that primary mediastinal DLBCL and highgrade B-cell lymphomas should be treated with more intense chemotherapy regimens, such as DA-EPOCH - R (doseadjusted etoposide, doxorubicin, and cyclophosphamide with vincristine, prednisone, and rituximab) [24,25]. There is still no standard approach regarding the treatment regimen to be followed for cases with renal involvement. However, successful cases of treatment with the DA-EPOCH-R regimen have been reported in the literature [26,27].

In conclusion, renal involvement in DLBCL is rare, however, it is associated with poor prognosis. Moreover, it involves an increased risk for CNS recurrence. Therefore, CNS prophylaxis is recommended for such patients. However, randomized controlled trials are required to establish a standard treatment approach.

\section{REFERENCES}

[1] Morgan G, Vornanen M, Puitinen J, et al. Changing trends in the incidence of non-Hodgkin's lymphoma in Europe. Biomed Study Group. Ann Oncol 1997;8 Suppl 2:49-54.

[2] Moller MB, Pedersen NT, Christensen BE. Diffuse large B-cell lymphoma: clinical implications of extranodal versus nodal presentation-a population-based study of 1575 cases. Br J Haematol 2004;124:151-9.

[3] Takahashi H, Tomita N, Yokoyama M, et al. Prognostic impact of extranodal involvement in diffuse large B-cell lymphoma in the rituximab era. Cancer 2012;118:4166-72. doi:10.1002/ cncr.27381

[4] Villa D, Connors JM, Sehn LH, Gascoyne RD, Savage KJ. Diffuse large B-cell lymphoma with involvement of the kidney: outcome and risk of central nervous system relapse. Haematologica 2011;96:1002-7. doi:10.3324/ haematol.2011.041277

[5] Lopez-Guillermo A, Colomo L, Jimenez M, et al. Diffuse large B-cell lymphoma: clinical and biological characterization and outcome according to the nodal or extranodal primary origin. J Clin Oncol 2005;23:2797-804. doi:10.1200/JCO.2005.07.155

[6] Lehners N, Kramer I, Schwarzbich MA, Ho AD, WitzensHarig M. Analysis of clinical characteristics and outcome of patients with previously untreated diffuse large B-cell lymphoma and renal involvement in the rituximab era. Leuk 
Lymphoma 2016;57:2619-25. doi:10.3109/10428.194.2016.115 7869

[7] Tai WM, Chung J, Tang PL, et al. Central nervous system (CNS) relapse in diffuse large B cell lymphoma (DLBCL): pre-and post-rituximab. Ann Hematol 2011;90:809-18. doi:10.1007/s00277.010.1150-7

[8] Fletcher CD, Kahl BS. Central nervous system involvement in diffuse large B-cell lymphoma: an analysis of risks and prevention strategies in the post-rituximab era. Leuk Lymphoma 2014;55:2228-40. doi:10.3109/10428.194.2013.86 9326

[9] Villa D, Connors JM, Shenkier TN, Gascoyne RD, Sehn LH, Savage KJ. Incidence and risk factors for central nervous system relapse in patients with diffuse large B-cell lymphoma: the impact of the addition of rituximab to CHOP chemotherapy. Ann Oncol 2010;21:1046-52. doi:10.1093/annonc/mdp432

[10] Schmitz N, Zeynalova S, Glass B, et al. CNS disease in younger patients with aggressive B-cell lymphoma: an analysis of patients treated on the Mabthera International Trial and trials of the German High-Grade Non-Hodgkin Lymphoma Study Group. Ann Oncol 2012;23:1267-73. doi:10.1093/annonc/ mdr440

[11] Tomita N, Takasaki H, Ishiyama $\mathrm{Y}$, et al. Intrathecal methotrexate prophylaxis and central nervous system relapse in patients with diffuse large B-cell lymphoma following rituximab plus cyclophosphamide, doxorubicin, vincristine and prednisone. Leuk Lymphoma 2015;56:725-9. doi:10.310 9/10428.194.2014.931953

[12] Ferreri AJ, Bruno-Ventre M, Donadoni G, et al. Risk-tailored CNS prophylaxis in a mono-institutional series of 200 patients with diffuse large B-cell lymphoma treated in the rituximab era. Br J Haematol 2015;168:654-62. doi:10.1111/bjh.13194

[13] Cheah CY, Seymour JF. Central nervous system prophylaxis in non-Hodgkin lymphoma: who, what, and when? Curr Oncol Rep 2015;17:25. doi:10.1007/s11912.015.0450-4

[14] Pfreundschuh M, Schubert J, Ziepert M, et al. Six versus eight cycles of bi-weekly CHOP-14 with or without rituximab in elderly patients with aggressive CD20+ B-cell lymphomas: a randomised controlled trial (RICOVER-60). Lancet Oncol 2008;9:105-16. doi:10.1016/S1470-2045(08)70002-0

[15] Pfreundschuh M, Trumper L, Osterborg A, et al. CHOPlike chemotherapy plus rituximab versus CHOP-like chemotherapy alone in young patients with good-prognosis diffuse large-B-cell lymphoma: a randomised controlled trial by the MabThera International Trial (MInT) Group. Lancet Oncol 2006;7:379-91. doi:10.1016/S1470-2045(06)70664-7

[16] Delarue R, Tilly H, Mounier N, et al. Dose-dense rituximabCHOP compared with standard rituximab-CHOP in elderly patients with diffuse large B-cell lymphoma (the LNH03-6B study): a randomised phase 3 trial. Lancet Oncol 2013;14:52533. doi:10.1016/S1470-2045(13)70122-0

[17] Pfreundschuh M, Poeschel V, Zeynalova S, et al. Optimization of rituximab for the treatment of diffuse large B-cell lymphoma (II): extended rituximab exposure time in the
SMARTE-R-CHOP-14 trial of the german high-grade nonHodgkin lymphoma study group. J Clin Oncol 2014;32:412733. doi:10.1200/JCO.2013.54.6861

[18] Ziepert M, Hasenclever D, Kuhnt E, et al. Standard International prognostic index remains a valid predictor of outcome for patients with aggressive CD20+ B-cell lymphoma in the rituximab era. J Clin Oncol 2010;28:237380. doi:10.1200/JCO.2009.26.2493

[19] Canet E, Zafrani L, Lambert J, et al. Acute kidney injury in patients with newly diagnosed high-grade hematological malignancies: impact on remission and survival. PLoS One 2013;8:e55870. doi:10.1371/journal.pone.0055870

[20] Coiffier B, Thieblemont C, Van Den Neste E, et al. Long-term outcome of patients in the LNH-98.5 trial, the first randomized study comparing rituximab-CHOP to standard $\mathrm{CHOP}$ chemotherapy in DLBCL patients: a study by the Groupe d'Etudes des Lymphomes de l'Adulte. Blood 2010;116:2040-5. doi:10.1182/blood-2010-03-276246

[21] Feugier P, Van Hoof A, Sebban C, et al. Long-term results of the R-CHOP study in the treatment of elderly patients with diffuse large B-cell lymphoma: a study by the Groupe d'Etude des Lymphomes de l'Adulte. J Clin Oncol 2005;23:4117-26. doi:10.1200/JCO.2005.09.131

[22] Pfreundschuh M, Kuhnt E, Trumper L, et al. CHOP-like chemotherapy with or without rituximab in young patients with good-prognosis diffuse large-B-cell lymphoma: 6-year results of an open-label randomized study of the MabThera International Trial (MInT) Group. Lancet Oncol 2011;12:101322. doi:10.1016/S1470-2045(11)70235-2

[23] Habermann TM, Weller EA, Morrison VA, et al. Rituximab$\mathrm{CHOP}$ versus $\mathrm{CHOP}$ alone or with maintenance rituximab in older patients with diffuse large B-cell lymphoma. J Clin Oncol 2006;24:3121-7. doi:10.1200/JCO.2005.05.1003.

[24] Howlett C, Snedecor SJ, Landsburg DJ, et al. Front-line, dose-escalated immunochemotherapy is associated with a significant progression-free survival advantage in patients with double-hit lymphomas: a systematic review and metaanalysis. Br J Haematol 2015;170:504-14. doi:10.1111/ bjh. 13463

[25] Dunleavy K, Pittaluga S, Maeda LS, et al. Dose-adjusted EPOCH-rituximab therapy in primary mediastinal B-cell lymphoma. N Engl J Med 2013;368:1408-16. doi:10.1056/ NEJMoa1214561

[26] Hanna F, Prakash A, Allan E, Khalafallah AA. Successful treatment of concomitant metastatic prostate cancer and B-cell non-Hodgkin's lymphoma with R-EPOCH chemotherapy regimen and antiandrogen therapy. BMJ Case Rep 2018;2018. doi:10.1136/bcr-2017-223637

[27] Kaur A, Abughanimeh O, Zafar Y, Pluard T. Diffuse large B-cell lymphoma presenting as bilateral renal masses: Successful treatment with dose-adjusted REPOCH (Rituximab, Etoposide, Prednisone, Vincristine, Cyclophosphamide, Doxorubicin) chemotherapy regimen. Cureus 2019;11:e3814. doi: $10.7759 /$ cureus.3814 